\title{
The Relationship between Preseason Common Screening Tests to Identify Inter-Limb Asymmetries in High-Level Senior and Professional Soccer Players
}

\author{
Fernando J. Santos ${ }^{1,2,3}$, Aníbal J. Valido ${ }^{4,5}$, Inês S. Malcata ${ }^{4}$, Cátia C. Ferreira ${ }^{1,6}$, Dalton M. Pessôa Filho ${ }^{7,8}{ }^{(\mathbb{C} \text {, }}$ \\ Carlos E. L. Verardi $8,9 \oplus$ and Mário C. Espada $1,3,4, * \mathbb{B}$ \\ 1 Polytechnic Institute of Setúbal, School of Education, 2914-504 Setúbal, Portugal; \\ fernando.santos@ese.ips.pt (F.J.S.); catia.ferreira@ese.ips.pt (C.C.F.) \\ 2 Faculty of Human Kinetics, University of Lisbon, 1499-002 Cruz Quebrada, Portugal \\ 3 Life Quality Research Centre, Complexo Andaluz, Apartado, 2040-413 Rio Maior, Portugal \\ 4 Polytechnic Institute of Setúbal, School of Technology (ESTSetúbal, CDP2T), 2914-508 Setúbal, Portugal; \\ anibal.valido@estsetubal.ips.pt (A.J.V.); ines.malcata@estudantes.ips.pt (I.S.M.) \\ 5 Centre for Marine Technology and Ocean Engineering (CENTEC), Instituto Superior Técnico, \\ Universidade de Lisboa, 1049-001 Lisbon, Portugal \\ 6 Research Group in Optimization of Training and Sport Performance (GOERD), Faculty of Sports Sciences, \\ University of Extremadura, 10003 Caceres, Spain \\ 7 Department of Physical Education, São Paulo State University (UNESP), Bauru 17033-360, Brazil; \\ dalton.pessoa-filho@unesp.br \\ check for \\ updates \\ Citation: Santos, F.J.; Valido, A.J.; \\ Malcata, I.S.; Ferreira, C.C.; Pessôa \\ 8 Graduate Programme in Developmental Psychology and Learning, Faculty of Science, \\ São Paulo State University (UNESP), Bauru 17033-360, Brazil; carlos.verardi@unesp.br \\ 9 Graduate Programme in Human Development and Technology, São Paulo State University (UNESP), \\ Rio Claro 13506-900, Brazil \\ * Correspondence: mario.espada@ese.ips.pt; Tel.: +351-265-710-800
} Filho, D.M.; Verardi, C.E.L.; Espada, M.C. The Relationship between Preseason Common Screening Tests to Identify Inter-Limb Asymmetries in High-Level Senior and Professional Soccer Players. Symmetry 2021, 13, 1805. https://doi.org/ 10.3390/sym13101805

Academic Editor: John H. Graham

Received: 31 August 2021

Accepted: 23 September 2021

Published: 28 September 2021

Publisher's Note: MDPI stays neutral with regard to jurisdictional claims in published maps and institutional affiliations.

Copyright: (c) 2021 by the authors. Licensee MDPI, Basel, Switzerland. This article is an open access article distributed under the terms and conditions of the Creative Commons Attribution (CC BY) license (https:/ / creativecommons.org/licenses/by/ $4.0 /)$.

\begin{abstract}
This study sought to examine inter-limb asymmetries in common screening tests performed during preseason and to analyze the relationship between the performance in the different tests. Nineteen high-level senior and professional soccer players (age: $23.2 \pm 3.1$ years; height: $181 \pm 0.06 \mathrm{~cm}$; body mass: $75.2 \pm 4.8 \mathrm{~kg}$ ) performed several common screening tests during preseason: Dorsiflexion lunge test (DLT); bent knee fall out test (BKFO); y-balance anterior test (YBT A); y-balance posterolateral test (YBT PL); Y-balance posteromedial test (YBT PM); Heel-rise test (HRT) and single leg hamstring bridge test (SLHBT). High levels of reliability (ICC $>0.88$ and $<0.94$ ) were observed in all the studied variables. Inter-limb significant differences were observed in DLT and YBT PM test $(p<0.01)$ but YBT A, HRT and SLHBT presented trivial effect size (ES) (0.03; 0.07 and 0.13 , respectively), contrary to DLT, BKFO and YBT PL, all with small ES $(0.20 ;-0.23$ and -0.22) and YBT PM, which revealed very large ES (2.91). Considering all data, high-level senior and professional soccer players present fairly good mean values of lower limb symmetry. Performance considering all tests was different, a fact associated with different biomechanical dynamics (e.g., YBT), nonetheless, the correlations between tests underline the relationship between these, which could represent important evidence to consider for injury prevention and performance enhancement programs.
\end{abstract}

Keywords: soccer; inter-limb; symmetry; biomechanical; injury risk; performance

\section{Introduction}

Today's sporting demands are higher than in the past [1], and soccer is a multifaceted team sport where the specific physical fitness attributes of the players justify particular approaches and meticulous analysis in scientific research [2]. It has become popular worldwide, causing competitive moments to increment, involving highly prepared and specialized players [3]. During practice and competition, soccer players are exposed to 
large volumes of repetitive high-intensity short-duration actions [4], accordingly, this sport is associated to a high injury risk, which may have a negative impact on both team performance and individual players' health [5].

Injuries in sports are associated to complexity [6], consequently, a holistic approach seems to be essential to increase the probability of success [7]. Recently it was stressed that non-contact injuries occur most frequently in male youth soccer players, with knee and ankle indicated as having the highest incidence [8]. Moreover, epidemiological studies highlighted that muscle injuries constitute more than one-third of all injuries produced during a competitive season [8,9], causing more than a quarter of the total injury absence in professional soccer clubs [9]. Considering a squad of 25 soccer players, it was previously indicated that clubs may experience an average of 12 to 15 muscle injuries [10], associated to around 300 time-loss days [11,12].

Due to its specific characteristics, the hamstrings are the muscle group with the highest injury incidence in both senior $[10,13]$ and young [14] elite male soccer players, associated to high re-injury rates in soccer (12-45\%) [15]. In soccer alone, hamstring strain injuries (HSI) represent $12 \%$ of total injuries in high-level players [16]. Depending on the time of the season and competitive scheduling, this could represent six fixtures being missed, with professional soccer teams often experiencing 5-6 HSI per season [10]. Therefore, this specific injury results in a large performance and financial burden, costing elite European soccer teams in the region of half a million euros, and this scenario is likely to have increased when considering inflation since 2016 [13]. Even more alarming is the reported $4 \%$ annual increase in HSI occurrence in soccer during a 13-year longitudinal study [13]. These facts highlight and suggest the importance of collaborative work, namely performed by professionals from different fields such as sport sciences, physiotherapy and biomedical technology.

Dynamic balance is the ability to stabilize the body and maintain center of mass stability during dynamic actions, which is extremely relevant for the successful performance of fundamental movement skills [17], many of them important for success during a soccer game. Reduced dynamic balance scores have been associated with lower extremity injuries [18], more specifically, the sum of three out of eight reach directions in the star excursion balance test (anterior, posteromedial, and posterolateral) and asymmetrical anterior reach distances have shown associations with injury in male youth athletes $[19,20]$.

Inter-limb asymmetry is defined as differences in the function or performance between limbs [21]. These are common in sports, with particular emphasis in soccer, where players are exposed to a very congested playing calendar and high volumes of training [22]. Asymmetry thresholds between $10 \%$ and $15 \%$ have been highlighted to impact different aspects of performance testing [23], nevertheless, it is unclear if asymmetry thresholds for professional soccer players are consistent across different tests and recently, it was indicated that asymmetries were task and variable specific [24].

Hodges et al. [21] stressed that functional asymmetries may occur from a multitude of sources, including strength, anthropometry, and neurology, underlining that asymmetry and poor alignment lead to increased energy expenditure, and decreased muscular efficiency, which ultimately leads to increased stress and fatigue. The risk of injury in lower limbs was also previously associated to a multivariate nature, Hägglund et al. [15] indicated intrinsic risk factors such as poor flexibility, previous injury, older age, and decreased muscle imbalance or strength, and extrinsic risk factors, namely match play association with an increased rate of muscle injury, referring to the evidence that muscle injuries occur more frequently toward the end of matches.

More recently, Read et al. [22] evaluated male soccer players from the Qatar Stars League, categorizing the asymmetry thresholds in the bent knee fall out test (BKFO) in a quartile perspective: Q1 (small $\leq 5.7 \%), \mathrm{Q} 2$ (moderate $=5.8-12.5 \%), \mathrm{Q} 3(12.6-20.9 \%$ ) and Q4 ( $\geq 215)$ and it was also previously found that bilateral difference in concentric knee extensor torque measured at $240^{\circ}$ per second is related to faster times in a $40 \mathrm{~m}$ sprint [25]. Evaluating inter-limb asymmetries among athletes was indicated as crucial [26], thus, a 
detailed analysis of inter-limbs differences across a range of commonly used screening tests is very relevant to determine variable-specific thresholds for asymmetry.

Likewise, the relationship between different common screening tests performed in preseason may shed light about possibilities for performance enhancement and injury risk prevention. Understanding whether inter-limb asymmetries are associated to high-level senior and professional soccer players is of great interest for soccer teams and research, as studies that compare to younger soccer players are scarce due to high training frequency and massive competitive schedule. Hence, the aim of the present study was to examine inter-limb asymmetries in common screening tests performed during preseason by highlevel senior and professional soccer players and to analyze the relationship between the performance in the different tests.

\section{Materials and Methods}

\subsection{Participants}

Nineteen high-level senior and professional soccer players (23.2 \pm 3.1 years of age; $181 \pm 0.06 \mathrm{~cm}$ of height; $75.2 \pm 4.8 \mathrm{~kg}$ of body mass; minimum 12 years of training experience), were involved in the study. All athletes maintained regular training (3-4 h per day, 5 days per week) in the preceding 12 months before participation in the research. Subjects were free from injury three months prior to data collection and at the time of testing. The soccer team squad was composed by 26 players. The reasons associated with non-participation of seven players were: injury associated to surgical intervention in the 18 months before data collection or injury associated to absent from training more than 7 days in the 12 months before testing.

The research was conducted according to the international ethical standards for sport and exercise science research [27] and in accordance with the Declaration of Helsinki. This study was submitted to the Ethical Committee of São Paulo State University (UNESP), which was registered and approved under (CAAE: 02523412.4.0000.5398, final report no: 237.707). Institutional authorization was obtained prior to approaching the athletes, and all these, of legal age, provided written informed consent.

\subsection{Study Design}

Subjects were tested in 2020-2021 preseason (August 2020), to avoid circadian rhythms effect at the same time of day on the two testing moments, each separated by $24 \mathrm{~h}$. All players were to refrain from intense training at least $48 \mathrm{~h}$ prior to data collection and arrived at the gym wearing comfortable athletic clothing.

Prior to testing, each participant performed a dynamic warm-up, which all participants were accustomed in daily practice. Body mass $(\mathrm{kg})$ was assessed on a calibrated physician scale (Seca 786 Culta, Milan, Italy). Height (cm) was measured on a measurement platform (Seca 274, Milan, Italy).

\subsection{Procedures}

The first session was utilized to familiarize all participants with testing procedures, providing the opportunity to soccer players to practice as they wanted, even though in all cases, participants were instructed to practice each test a minimum of five times. Data collection occurred in the second session.

Tests were performed in a standardized order. Firstly, the participants received standardized instructions orally regarding the test execution, the staff and research team members also demonstrated the test performance. All subjects then completed one trial with feedback and, if necessary, received further visual, oral and/or manual instructions guidance. This was performed to guarantee full interpretation of the test performance and to confirm that the test result did not reflect the subject's unfamiliarity with the movement.

Afterward, athletes performed the tests, simultaneously assessed by two observers. As communication is a relevant element in the coach-athlete relationship [28] and may 
influence players performance, during the testing no motivational communication occurred, and the observers were blinded to each other's scores.

All tests were performed twice, and the arithmetic mean considered, except in Ybalance test (YBT) where three attempts were performed for anterior (A), posterolateral $(\mathrm{PL})$ and posteromedial $(\mathrm{PM})$ reach.

\subsection{Testing Description}

\subsubsection{Dorsiflexion Lunge Test (DLT)}

The test was completed with weight discharge, placing the anterior extremity of the foot perpendicularly in contact with the wall and the knee also supported on the wall. Subjects were then asked to remove the foot from the wall by sliding it back so that the knee did not lose contact with the wall and the heel of the tested foot did not lose contact with the ground. The maximum distance between the anterior extremity of the foot and the wall was measured with tape measure. Distances shorter than 9 to $10 \mathrm{~cm}$ suggest dorsiflexion restriction, and this test was previously indicated as predictive of future soccer injuries [29].

\subsubsection{Bent Knee Fall Out (BKFO)}

Used to measure hip range of motion combining hip flexion, abduction, and external rotation. The BKFO test is performed in a crook lying position. The knees are flexed to a $90^{\circ}$ position using a universal goniometer. Afterward, the knees are moved outward while keeping the soles of the feet together. At the end of the range of movement, gentle overpressure is given by the examiner to ensure a relaxed position. The distance from the fibular head to the top of the table is then measured in $\mathrm{cm}$ with a semirigid tape measure to the nearest $0.5 \mathrm{~cm}$.

\subsubsection{Y-Balance Test (YBT)}

The test is important to measure the single-leg balance ability, distance reached by the lower limb in three directions (A, PL, and PM) from the single-leg standing position with the subject's hand placed on the hip. This instrument was used to assess lower limb stability with procedures according with Plisky et al. [18] protocol. The soccer player stood in monopodal stance in the center of an inverted Y-shape on the leg to be evaluated. Three attempts were performed for each reaching direction. The distance was measured in $\mathrm{cm}$, and the arithmetic mean of three attempts made in each range was calculated [30].

\subsubsection{Heel-Rise Test (HRT)}

Athletes performed a maximal number of single-legged heel rises on an $10^{\circ}$ incline (e.g., slight dorsiflexion position). To assist balance, subjects were permitted to apply fingertip support at shoulder height on a wall in front of them. Heel-rise cycle cadence was controlled at 60 per minute by a metronome, which corresponds to an ankle angular velocity of approximately $60^{\circ}$ per second. Individuals were instructed to lift the heel as high as possible for each heel rise until no further repetitions could be performed, keeping the knee and trunk straight. The test was concluded when subjects could no longer: (1) lift the stance heel from the incline or repeat a complete heel-rise cycle; (2) maintain the set pace, knee angle or trunk position; or (3) rely on fingertip support for balance and used the wall to assist performance. The number of correct heel-rises completed was counted for each leg and used as outcome score.

\subsubsection{Single Leg Hamstring Bridge Test (SLHBT)}

Athletes lied down on the ground with one heel on a $60 \mathrm{~cm}$ high box (knee flexed to approximately $20^{\circ}$ and hip flexed to approximately $45^{\circ}$ ). Players were then instructed to push down through the heel to lift their bottom off the ground while holding their arms crossed over their chest. Repetition was considered regular when the individual touched the ground and then extended their hip to $0^{\circ}$ without resting on the ground. This is a strength endurance hamstring test where the individual performs repetitions until 
exhaustion, and the test ends when: (1) technique becomes irregular, or (2) the individual cannot proceed with the test due to fatigue. The number of successful repetitions for each leg (right and left) is the main outcome measure of the test.

\subsection{Statistical Analysis}

The sample size required was determined beforehand (GPower, v.3.1.9, University of Kiel, Kiel, Germany). All data was initially computed as means and standard deviations (SD) in Microsoft Excel ${ }^{\mathrm{TM}}$ and all additional analyses computed in SPSS v.25.0 (SPSS Inc., Chicago, IL, USA). The Shapiro-Wilk test was performed to check the normality of data. The comparison between the data obtained with the left and right lower limb was made through the $t$-test. The effect size (ES) was calculated through Cohens $d$, having been considered trivial (0-0.2), small (0.2-0.6), moderate (0.6-1.2), large (1.2-2), very large (2-4) and extremally large (>4) [31]. Linear regression models between different test results were computed. Trendline equation and determination coefficient $\left(\mathrm{R}^{2}\right)$ were calculated. The session reliability of test measures was computed using intraclass correlation coefficient (ICC) with absolute agreement and 95\% confidence interval. Interpretation of ICC values was in accordance with previous research [32], where values $>0.9=$ excellent, 0.75-0.9 = good, $0.5-0.75=$ moderate, and $<0.5=$ poor. Pearson's linear correlation coefficient was used to test the relationships between the study variables. Statistical significance was accepted at $p \leq 0.05$.

\section{Results}

High levels of reliability (ICC $>0.88$ and $<0.94$ ) were observed in all the studied variables. Descriptive statistics displaying mean \pm standard deviation $(M \pm S D)$ of performance in all tests and mean difference between lower limbs (right- $\mathrm{R} / \mathrm{left}-\mathrm{L}$ ) in percentage $(\%)$ and unit are presented in Table 1.

Table 1. Performance in the tests with percentage and unit differences.

\begin{tabular}{|c|c|c|c|}
\hline Test & $\mathbf{M} \pm \mathbf{S D}$ & $\begin{array}{c}\text { Mean Dif } \\
\text { (L vs. R) } \\
(\%)\end{array}$ & $\begin{array}{c}\text { Mean Dif } \\
\text { (L vs. R) } \\
\text { Unit }\end{array}$ \\
\hline $\begin{array}{l}\operatorname{DLT}(\mathrm{L})(\mathrm{cm}) \\
\operatorname{DLT}(\mathrm{R})(\mathrm{cm})\end{array}$ & $\begin{array}{l}12.00 \pm 3.78^{*} \\
12.74 \pm 3.55^{*}\end{array}$ & 6.14 & 0.74 \\
\hline $\begin{array}{l}\text { BKFO (L) (cm) } \\
\text { BKFO (R) (cm) }\end{array}$ & $\begin{array}{l}19.72 \pm 3.42 \\
19.00 \pm 2.92\end{array}$ & 3.79 & 0.72 \\
\hline $\begin{array}{l}\text { YBT A (L) }(\mathrm{cm}) \\
\text { YBT A (R) }(\mathrm{cm})\end{array}$ & $\begin{array}{l}75.77 \pm 6.27 \\
75.96 \pm 6.43\end{array}$ & 0.25 & 0.19 \\
\hline $\begin{array}{l}\text { YBT PL (L) }(\mathrm{cm}) \\
\text { YBT PL (R) (cm) }\end{array}$ & $\begin{array}{l}96.30 \pm 5.13 \\
95.11 \pm 5.50\end{array}$ & 1.25 & 1.19 \\
\hline $\begin{array}{l}\text { YBT PM (L) (cm) } \\
\text { YBT PM (R) (cm) }\end{array}$ & $\begin{array}{l}94.02 \pm 7.06^{\#} \\
94.93 \pm 6.29^{\#}\end{array}$ & 0.97 & 0.91 \\
\hline $\begin{array}{l}\text { HRT (L) (reps) } \\
\text { HRT (R) (reps) }\end{array}$ & $\begin{array}{l}40.58 \pm 18.51 \\
39.42 \pm 15.82\end{array}$ & 2.94 & 1.16 \\
\hline $\begin{array}{l}\text { SLHBT (L) (reps) } \\
\text { SLHBT (R) (reps) }\end{array}$ & $\begin{array}{l}62.63 \pm 30.03 \\
59.11 \pm 22.90\end{array}$ & 5.97 & 3.52 \\
\hline
\end{tabular}

Dorsiflexion lunge test (DLT); bent knee fall out (BKFO); Y-balance anterior test (YBT A); Y-balance posterolateral test (YBT PL); Y-balance posteromedial test (YBT PM); heel-rise test (HRT); single leg hamstring bridge test (SLHBT); ${ }^{*, \#}$ significant difference $(p<0.01)$.

DLT (L) was correlated to YBT A (L) $(r=0.49, p<0.05)$ and YBT PM (L) $(r=0.55$, $p<0.05)$, the same was observed regarding the same tests and right lower $\operatorname{limb}(\mathrm{r}=0.51$, $p<0.05$ and $r=0.59, p<0.01$, respectively). Inter-limb significant differences were observed in DLT and YBT PM tests $(p<0.01)$. The linear regressions with $r^{2}$ values between the lower limbs are shown in Figure 1. 

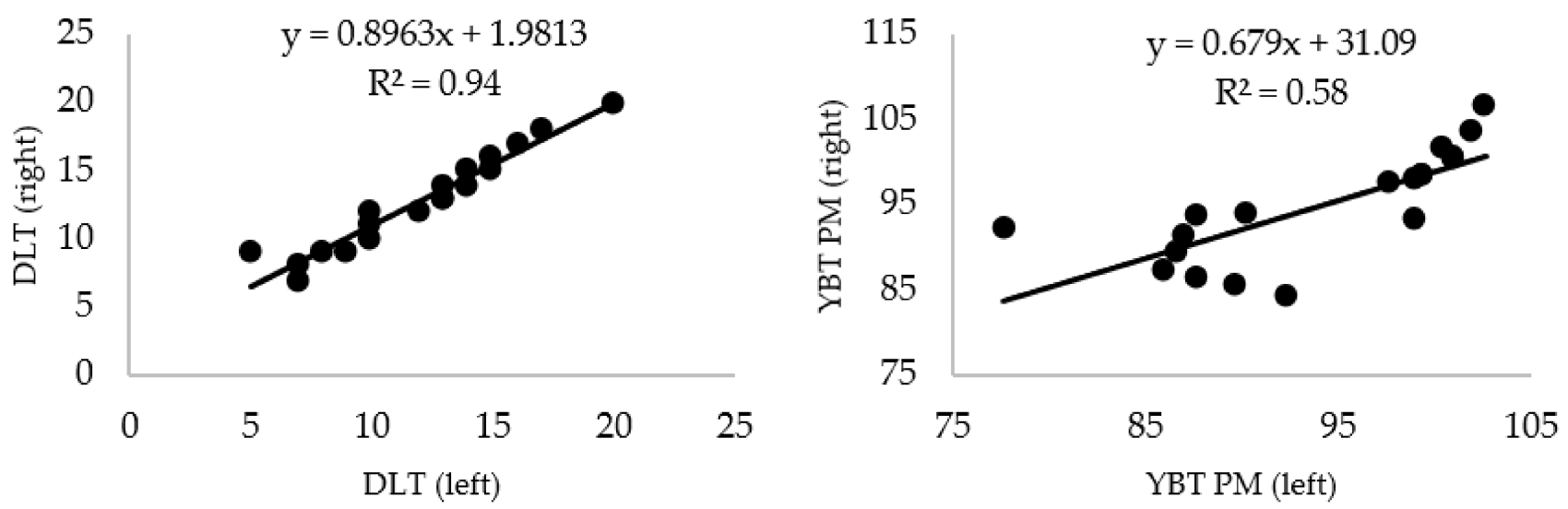

Figure 1. Inter-limb linear regression of dorsiflexion lunge test and y-balance posteromedial test.

DLT inter-limb performance was significantly different $(p<0.01)$; despite that, regression analysis adjusted $\mathrm{r}^{2}$ value (0.94) indicated a good estimation model, contrary to the observed in YBT PM test considering inter-limb relationship (0.58). No difference in-between limbs were observed in endurance tests related to Hamstring and Calf muscles (SLHBT and HRT, respectively). Figure 2 depicts the regression analysis adjusted $\mathrm{r}^{2}$ values supporting the results, indicating a fairly good estimation model.
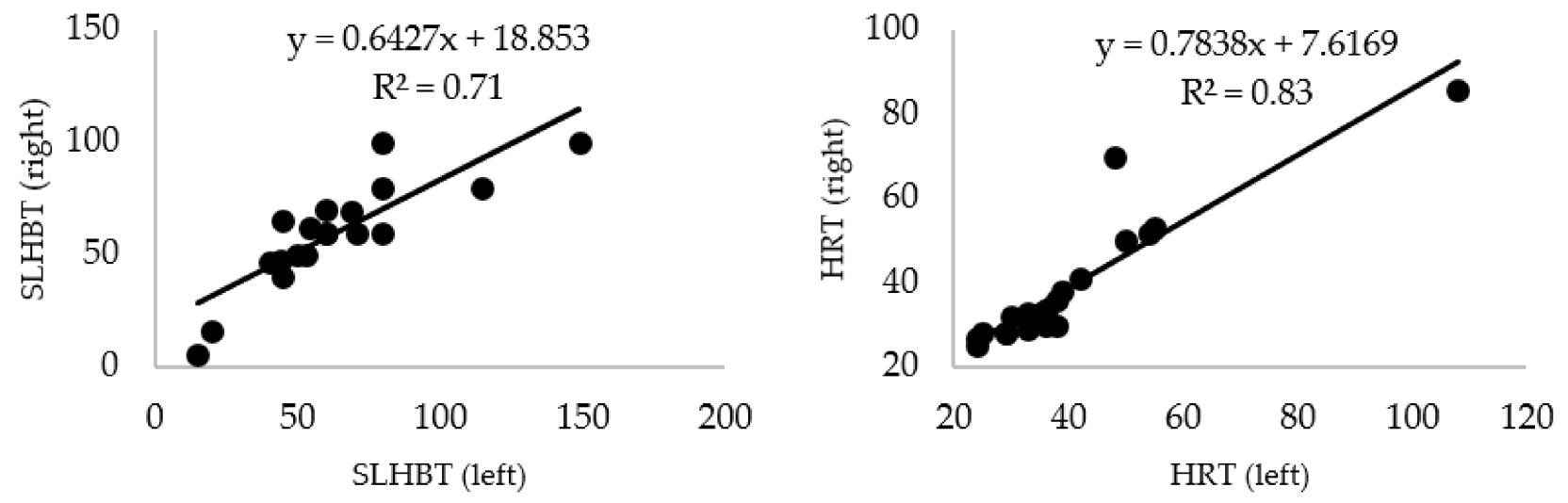

Figure 2. Inter-limb linear regression of single leg hamstring bridge test and heel-rise test.

YBT A (L) was correlated to YBT PL (L) $(r=0.49, p<0.05)$ and YBT PM (L) $(r=0.84$, $p<0.01)$. YBT A (R) was correlated to YBT PM (R) $(\mathrm{r}=0.47, p<0.01)$ and SLHBT (R) $(\mathrm{r}=-0.49, p<0.05)$. YBT PL $(\mathrm{R})$ was only correlated to YBT PM $(\mathrm{R})(\mathrm{r}=0.66, p<0.01)$. SLHBT (L) was also only correlated to HRT (L) $(\mathrm{r}=0.77, p<0.01)$.

YBT A, HRT and SLHBT presented trivial ES $(0.03 ; 0.07$ and 0.13 , respectively), contrary to DLT, BKFO and YBT PL, all with small ES $(0.20 ;-0.23$ and -0.22$)$ and YBT PM, which revealed very large ES (2.91). Schematic representation of ES in the different tests is shown in Figure 3. 


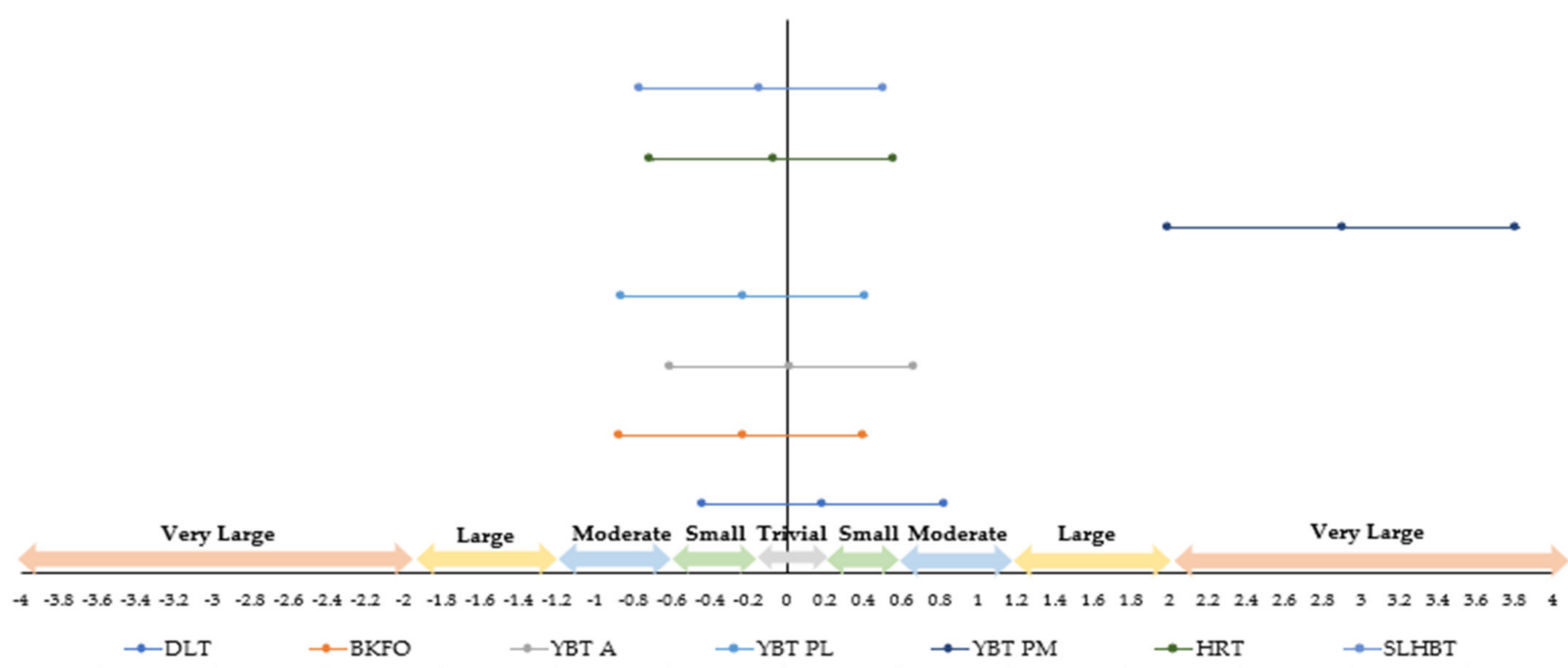

Figure 3. Dorsiflexion lunge test (DLT); bent knee fall out (BKFO); Y-balance anterior test (YBT A); Y-balance posterolateral test (YBT PL); Y-balance posteromedial test (YBT PM); heel-rise test (HRT); single leg hamstring bridge test (SLHBT). ES are considered trivial (0-0.2), small (0.2-0.6), moderate (0.6-1.2), large (1.2-2), very large (2-4) and extremely large (>4) (Cohen's d).

\section{Discussion}

The purpose of this study was to examine inter-limb asymmetries in common screening tests performed during preseason by high-level senior and professional soccer players and to analyze the relationship between the performance in the different tests. To the best of the author's knowledge, this is the first study which comprehensively investigates a large number of common screening tests in preseason with high-level senior and professional soccer players to evaluate inter-limb asymmetries and the relationship between the performance in all of them. The major findings were: (i) considering all the common performed screening tests, high-level senior and professional soccer players reveal good inter-limb levels of symmetry; (ii) inter-limb differences were different in the performed tests, with inter-limbs statistically significant differences only observed in DLT and YBT PM; (iii) correlations between performance in the tests highlight that tendentially, the improvement of performance in one test may led to improvements in other tests; (iv) detailed and individual analysis is of relevant importance when analyzing high-level senior and professional soccer players.

Soccer requires specific development of each player considering the individual and group perspectives, namely efficient collective organization [33], associated with complexity in collective and individual actions performed by the players [34]. This team sport is associated to dynamic movements such as quick changes-of-direction, impulsive reactions, and short and long sprints, involving repetitive turning, stopping, and jumping motions [35], various of these and other skills requiring players to frequently repeat the execution of unilateral and asymmetric movements (e.g., kicking and changing direction). The limb differences in athletes may be related to the asymmetric motor demands, resulting in functional asymmetric adaptions [36] to allow them to perform within their sport [37], as performance enhancement is closely and decisively related with athlete's performance in training and competition, which is associated to the accuracy in identifying training task intensities towards the optimization of daily preparation [38].

Recent research evidenced larger inter-limb asymmetry to be related with reduced physical performance measures in athletes [39-41], compromising technical efficiency in sports activities. Björklund et al. [42] found maximum HRT counts mean values of $40 \pm 10$ in the right limb and $39 \pm 10$ in the left limb in well-trained male cross-country skiers $(21.7 \pm 3.8$ years of age) and in elite junior soccer plyers (17.7 \pm 0.5 years of age), after a 10-week training program associated to Nordic hamstring exercise (NHE) and Russian belt (RB), higher performances in SLHB were associated to NHE compared to RB training in 
right (49.12 \pm 11.48 reps vs. $48.13 \pm 10.30$ reps) and left lower limbs (51.31 \pm 11.83 reps vs. $50.33 \pm 11.98$ reps) [43].

With respect to DLT, dominant lower limb mean scores of $10.2 \pm 3.2 \mathrm{~cm}$ and nondominant of $10.1 \pm 3.1 \mathrm{~cm}$ were monitored in professional soccer players competing in Qatar Stars League (24.4 \pm 4.7 years of age), moreover, and considering BKFO, dominant and non-dominant lower limb mean scores of $14.0 \pm 4.0 \mathrm{~cm}$ and $13.9 \pm 4.2 \mathrm{~cm}$, respectively, were also observed in the soccer players [44]. Considering YBT and the different lower limbs, Shaffer et al. [45] observed similar inter-limb performances in active military during training (ages between 18 and 35 years old, 53 males and 11 females) considering A (left $57.8 \pm 6.8 \mathrm{~cm}$ vs. right $57.6 \pm 7.1 \mathrm{~cm}$ ) PL (left $93.2 \pm 8.5 \mathrm{~cm}$ vs. right $92.5 \pm 9.0 \mathrm{~cm}$ ) and $\mathrm{PM}$ reach (left $88.3 \pm 8.5 \mathrm{~cm}$ vs. right $89.1 \pm 9.4 \mathrm{~cm}$ ). The performances in our study with high-level senior and professional soccer players are close related to the observed in these studies, but globally better, evidence that we attribute to the level of training and in some cases also to the difference of age.

It has also previously been suggested that inter-limb asymmetries may be a result of the time spent competing in the same sport $[46,47]$, and as they are task variable and physical quality specific, no expectations should exist regarding the observation of the same inter-limbs differences across different screening tests [24]. The results of this study corroborate with this assumption, as inter-limb differences were different in the performed tests, with inter-limbs statistically significant differences only observed in DLT and YBT PM. It should be noted that despite this finding, the regression analysis adjusted $\mathrm{r}^{2}$ value in DLT revealed a good estimation model (0.94), and although the mean YBT PM scores were close $(\mathrm{L}=94.02 \pm 7.06 \mathrm{~cm}$ vs. $\mathrm{R}=94.93 \pm 6.29 \mathrm{~cm})$ the regression analysis adjusted $\mathrm{r}^{2}$ value and more specifically the ES revealed inter-limb asymmetries. These findings highlight that a detailed and individual analysis is of relevant importance when analyzing high-level senior and professional soccer players.

It was also highlighted by other authors that inter-limb asymmetries of $>15 \%$ in eccentric hamstrings strength are related to an increased injury incidence [48,49]. Thus, it is plausible that the prevalence of HSI may somewhat be influenced by their biarticular organization, the dual innervations of the biceps femoris and their muscle fiber-type distribution [50]. These anatomical characteristics negatively influences running coordination patterns, increasing the injury risk during running actions and eccentric muscle contractions [51], and coaches and practitioners should also consider that contraction timings and the chronic vs. acute load ratios, or accumulated loads, have a greater influence in injury risk, and consequently, should be considered in injury prevention programs.

In the past, it was also indicated that HSI occurred more frequently toward the end of each half of a $90 \mathrm{~min}$ soccer game (e.g., 30-45 $\mathrm{min}$ and 75-90 $\mathrm{min}$ ) [52,53]. One possible explanation regarding this topic relates to the evidence that differences in HSI between young and adult professional English soccer players may be partially justified by the evidence that professional players are able to self-pace when they perceive that an injury might occur, preventing muscle strains that may result in muscle tears [54]. It has also been stressed that the main etiological factors for the development of HSI include poor hamstring quadriceps ratio, the recurrence of previous injuries, muscle fatigue, and reduced hamstring flexibility $[16,55,56]$.

Our findings demonstrate that considering all the common screening tests performed by high-level senior and professional soccer players in our study, these reveal good interlimb levels of symmetry with results in SLHBT associated to trivial ES. The performance in SLHBT in our study ( $L=62.63 \pm 30.03$ reps vs. $R=59.11 \pm 22.90$ reps) was better compared to pre intervention period in Gaelic footballers, which revealed mean values in twelve athletes below the 40 repetitions [57]. This evidence supports the notion that specific dynamics associated to different sports may influence performance in common screening tests, in our study the endurance tests associated to Hamstrings and Calf muscles (SLHBT and HRT, respectively) revealed no significant differences and trivial ES. Another interesting finding was the correlation between performances in tests, evidencing that 
tendentially, the improvement of performance in one test may lead to improvements in other tests. This was particularly evident in YBT relationships between and with DLT and SLHBT, with this last presenting correlations in addition to YBT only with HRT, which highlights the biomechanical specificity between these tests associated to important muscles in soccer.

It should also be considered that the YBT test, and in particular the anterior reach direction, may be considered important given its association with injury risk [19,58]. More recently, anterior reach asymmetry was the unique YBT variable significantly associated with non-contact injury in collegiate athletes [58]. We have noticed in our study that YBT mean scores in the different perspectives (A, PL and PM reach) were always very close but further analysis revealed trivial ES in YBT A $(\mathrm{L}=75.77 \pm 6.27 \mathrm{~cm}$ vs. $\mathrm{R}=75.96 \pm 6.44 \mathrm{~cm})$, small ES in YBT PL $(\mathrm{L}=96.30 \pm 5.13 \mathrm{~cm}$ vs. $\mathrm{R}=95.11 \pm 5.50 \mathrm{~cm})$ and very large ES in YBT $\mathrm{PM}(\mathrm{L}=94.02 \pm 7.06 \mathrm{~cm}$ vs. $\mathrm{R}=94.93 \pm 6.29 \mathrm{~cm})$. These findings suggest that $\mathrm{YBT}$ scores although related, are task specific and that a deeper and individualized analysis is required in high-level senior and professional soccer players to determine inter-limb asymmetries.

Previous studies demonstrated that balance training should considered and incorporated in all stages of the athlete development, because balance training-induced improvements may support young athletes during the acquisition phase of complex movements and skills, and to withstand the demands of long-term athletic training and competition $[59,60]$. Thus, not only balance training but also flexibility and strength-training programs should be considered during soccer player training stages, as strength-training has been previously associated to a protective effect on injury severity [61]. Injury prevention strategies during daily practice are fundamental in soccer, namely in senior level because older age players can continue with soccer activity regardless of the presence of pain and reduced function, which is associated to increasing muscle damage [62].

It was stated that overall injuries are associated to two peaks in youth soccer players across a single season in September and January [8] and that the premature return to play of professional athletes may result in reinjuries [63], what is related to the evidence that training load in professional players is different compared to young players, and consequently, injury rates increase with age in male youth soccer players [52]. As injuries have an unfavorable impact on physical performance, a well-established preseason protocol associated to detailed analysis of the performed tests, would offer soccer teams and practitioners with more concrete information concerning their importance for soccer players performance enhancement and injury prevention. In our opinion this is pivotal not only for soccer, but for sport coaches as they play a key role in designing training sessions [64].

Some limitations should be considered when interpreting the findings of this study: (a) participants were high-level senior and professional soccer players, which is related to the possibility that the results cannot be directly applied to other age categories and soccer players of other levels; (b) the research was conducted in the beginning of the season (preseason, August), consequently, the commons screening tests protocols and results should not be applicable in other moments such as competitive moments. Future studies should consider increasing the sample size, in the sense of not being considered pilot studies, and explore the possibility to extend data collection in more teams of the same soccer league. It would also be interesting to investigate strength variables and evaluate other age categories and woman's soccer players. We also suggest that future studies consider the inclusion of acute and chronic loads and the evaluation of contraction of the musculature. Lastly, dominant, and non-dominant limb, playing positions analysis and intervention strategies should be considered to effectively address the inter-limb asymmetry concerns. 


\section{Conclusions}

High-level senior and professional soccer players present fairly good mean values of lower limb symmetry. Although, it should be noted that an in-depth and accurate analysis of performance should be considered aiming detecting injury risk. This study also revealed the need for an individual approach to data analysis.

Performance considering all tests was different, a fact associated with different biomechanical dynamics (e.g., YBT), nonetheless, the correlations between tests underline the relationship between these, which could represent important evidence to consider for injury prevention and performance enhancement programs.

The longitudinal tracking of performance in common screening tests in high-level senior and professional soccer players may be crucial to understanding their importance as part of a continued monitoring process with athletes. Finally, soccer club structure (chairs, directors, team managers, coaches, and others) should consider that regular training monitorization is vital and the collaborative work developed by professionals of difference areas such as sport sciences, physiotherapy and biomedical technology may represent an important support in the definition of assessment protocols and development of technology to improve the detection and prevention of injuries and, at the same time, improve sports performance.

Author Contributions: Conceptualization, F.J.S. and M.C.E.; methodology, F.J.S., M.C.E. and A.J.V.; formal analysis, F.J.S., M.C.E., A.J.V. and C.C.F.; investigation, F.J.S., M.C.E. and I.S.M.; supervision, F.J.S., M.C.E. and A.J.V.; data curation, F.J.S., M.C.E. and I.S.M.; writing-original draft preparation, M.C.E., I.S.M., D.M.P.F. and C.E.L.V.; writing-review and editing, F.J.S., M.C.E., A.J.V., I.S.M., C.C.F., D.M.P.F. and C.E.L.V.; visualization, F.J.S., M.C.E., A.J.V., I.S.M., C.C.F., D.M.P.F. and C.E.L.V.; funding acquisition, F.J.S. and M.C.E. All authors have read and agreed to the published version of the manuscript.

Funding: This research was funded by Foundation for Science and Technology, I.P., Grant/ Award Number UIDB/04748/2020. M.C.E. acknowledges the financial support from Polytechnic Institute of Setúbal.

Institutional Review Board Statement: The study considered the Declaration of Helsinki guidelines and was submitted to the Ethical Committee of São Paulo State University (UNESP), which was registered and approved under (CAAE: 02523412.4.0000.5398, final report $\left.n^{\circ}: 237.707\right)$.

Informed Consent Statement: Informed consent was obtained from all participants in the study.

Data Availability Statement: The data that support the findings of this study are available from the corresponding and first author (mario.espada@ese.ips.pt and fernando.santos@ese.ips.pt), upon reasonable request.

Conflicts of Interest: The authors declare no conflict of interest.

\section{References}

1. Santos, F.J.; Verardi, C.E.L.; de Moraes, M.G.; Filho, D.M.P.; Macedo, A.G.; Figueiredo, T.P.; Ferreira, C.C.; Borba, R.P.; Espada, M.C. Effects of Pitch Size and Goalkeeper Participation on Physical Load Measures during Small-Sided Games in Sub-Elite Professional Soccer Players. Appl. Sci. 2021, 11, 8024. [CrossRef]

2. Aurélio, J.; Dias, E.; Soares, T.; Espada, M.; Jorge, G.; Pessôa Filho, D.; Pereira, A.; Figueiredo, T. Relationship between body composition, anthropometry and physical fitness in under-12 soccer players of different positions. Int. J. Sports Sci. 2016, 6, 25-30. [CrossRef]

3. Santos, F.; Figueiredo, T.; Filho, D.; Verardi, C.; Macedo, A.; Ferreira, C.; Espada, M. Training Load in Different Age Category Soccer Players and Relationship to Different Pitch Size Small-Sided Games. Sensors 2021, 21, 5220. [CrossRef]

4. Suarez-Arrones, L.; Torreño, N.; Requena, B.; De Villarreal, E.S.; Casamichana, D.; Barbero-Alvarez, J.C.; Munguía-Izquierdo, D. Match-play activity profile in professional soccer players during official games and the relationship between external and internal load. J. Sports Med. Phys. Fit. 2015, 55, 1417-1422.

5. Hägglund, M.; Waldén, M.; Magnusson, H.; Kristenson, K.; Bengtsson, H.; Ekstrand, J. Injuries affect team performance negatively in professional football: An 11-year follow-up of the UEFA Champions League injury study. Br. J. Sports Med. 2013, 47, 738-742. [CrossRef] 
6. Hulme, A.; Finch, C.F. From monocausality to systems thinking: A complementary and alternative conceptual approach for better understanding the development and prevention of sports injury. Inj. Epidemiol. 2015, 2, 1-12. [CrossRef]

7. Bittencourt, N.; Meeuwisse, W.H.; Mendonça, L.; Nettel-Aguirre, A.; Ocarino, J.; Fonseca, S. Complex systems approach for sports injuries: Moving from risk factor identification to injury pattern recognition-narrative review and new concept. Br. J. Sports Med. 2016, 50, 1309-1314. [CrossRef]

8. Read, P.J.; Oliver, J.L.; Croix, M.B.A.D.S.; Myer, G.D.; Lloyd, R.S. An audit of injuries in six english professional soccer academies. J. Sports Sci. 2018, 36, 1542-1548. [CrossRef]

9. Renshaw, A.; Goodwin, P.C. Injury incidence in a Premier League youth soccer academy using the consensus statement: A prospective cohort study. BMJ Open Sport Exerc. Med. 2016, 2, e000132. [CrossRef]

10. Ekstrand, J.; Hägglund, M.; Waldén, M. Epidemiology of Muscle Injuries in Professional Football (Soccer). Am. J. Sports Med. 2011, 39, 1226-1232. [CrossRef]

11. Walden, M.; Hägglund, M.; Ekstrand, J. UEFA Champions League study: A prospective study of injuries in professional football during the 2001-2002 season. Br. J. Sports Med. 2005, 39, 542-546. [CrossRef] [PubMed]

12. Dvorak, J.; Junge, A.; Derman, W.; Schwellnus, M. Injuries and illnesses of football players during the 2010 FIFA World Cup. Br. J. Sports Med. 2011, 45, 626-630. [CrossRef]

13. Ekstrand, J.; Waldén, M.; Hägglund, M. Hamstring injuries have increased by $4 \%$ annually in men's professional football, since 2001: A 13-year longitudinal analysis of the UEFA Elite Club injury study. Br. J. Sports Med. 2016, 50, 731-737. [CrossRef]

14. Pfirrmann, D.; Herbst, M.; Ingelfinger, P.; Simon, P.; Tug, S. Analysis of Injury Incidences in Male Professional Adult and Elite Youth Soccer Players: A Systematic Review. J. Athl. Train. 2016, 51, 410-424. [CrossRef] [PubMed]

15. Hägglund, M.; Waldén, M.; Ekstrand, J. Risk Factors for Lower Extremity Muscle Injury in Professional Soccer. Am. J. Sports Med. 2012, 41, 327-335. [CrossRef] [PubMed]

16. Ekstrand, J.; Hägglund, M.; Waldén, M. Injury incidence and injury patterns in professional football: The UEFA injury study. Br. J. Sports Med. 2009, 45, 553-558. [CrossRef] [PubMed]

17. Faigenbaum, A.D.; Bush, J.A.; McLoone, R.P.; Kreckel, M.C.; Farrell, A.; Ratamess, N.A.; Kang, J. Benefits of Strength and Skill-based Training During Primary School Physical Education. J. Strength Cond. Res. 2015, 29, 1255-1262. [CrossRef]

18. Plisky, P.J.; Gorman, P.P.; Butler, R.J.; Kiesel, K.B.; Underwood, F.B.; Elkins, B. The Reliability of an Instrumented Device for Measuring Components of the Star Excursion Balance Test. N. Am. J. Sports Phys. Ther. NAJSPT 2009, 4, 92-99.

19. Plisky, P.J.; Rauh, M.J.; Kaminski, T.W.; Underwood, F.B. Star Excursion Balance Test as a Predictor of Lower Extremity Injury in High School Basketball Players. J. Orthop. Sports Phys. Ther. 2006, 36, 911-919. [CrossRef] [PubMed]

20. Hegedus, E.J.; McDonough, S.; Bleakley, C.; Baxter, D.; Cook, C. Clinician-friendly lower extremity physical performance tests in athletes: A systematic review of measurement properties and correlation with injury. Part 2-the tests for the hip, thigh, foot and ankle including the star excursion balance test. Br. J. Sports Med. 2015, 49, 649-656. [CrossRef]

21. Hodges, S.J.; Patrick, R.J.; Reiser, R.F. Effects of Fatigue on Bilateral Ground Reaction Force Asymmetries during the Squat Exercise. J. Strength Cond. Res. 2011, 25, 3107-3117. [CrossRef]

22. Read, P.J.; McAuliffe, S.; Bishop, M.C.; Oliver, J.L.; Graham-Smith, P.; Farooq, M.A. Asymmetry Thresholds for Common Screening Tests and Their Effects on Jump Performance in Professional Soccer Players. J. Athl. Train. 2021, 56, 46-53. [CrossRef] [PubMed]

23. Lockie, R.G.; Risso, F.G.; Lazar, A.; Giuliano, D.V.; Stage, A.A.; Liu, T.M.; Beiley, M.D.; Hurley, J.M.; Torne, I.A.; Stokes, J.J.; et al Between-Leg Mechanical Differences as Measured by the Bulgarian Split-Squat: Exploring Asymmetries and Relationships with Sprint Acceleration. Sports 2017, 5, 65. [CrossRef] [PubMed]

24. Grindem, H.; Snyder-Mackler, L.; Moksnes, H.; Engebretsen, L.; Risberg, M.A. Simple decision rules can reduce reinjury risk by 84\% after ACL reconstruction: The Delaware-Oslo ACL cohort study. Br. J. Sports Med. 2016, 50, 804-808. [CrossRef] [PubMed]

25. Lockie, R.G.; Schultz, A.B.; Jeffriess, M.D.; Callaghan, S.J. The relationship between bilateral differences of knee flexor and extensor isokinetic strength and multi-directional speed. Isokinet. Exerc. Sci. 2012, 20, 211-219. [CrossRef]

26. Dos'Santos, T.; Thomas, C.; Jones, P.A. Assessing Interlimb Asymmetries: Are We Heading in the Right Direction? Strength Cond. J. 2021, 43, 91-100. [CrossRef]

27. Harriss, D.; MacSween, A.; Atkinson, G. Ethical Standards in Sport and Exercise Science Research: 2020 Update. Int. J. Sports Med. 2019, 40, 813-817. [CrossRef]

28. Dos Santos, F.J.L.; Louro, H.G.; Espada, M.; Figueiredo, T.; Lopes, H.; Rodrigues, J. Relation of coaches' expectations with instruction and behavior of athletes. Cuad. Psicol. Deporte 2019, 19, 62-78. [CrossRef]

29. Clanton, T.; Matheny, L.M.; Jarvis, H.C.; Jeronimus, A.B. Return to Play in Athletes Following Ankle Injuries. Sports Health A Multidiscip. Approach 2012, 4, 471-474. [CrossRef]

30. Gonell, A.C.; Romero, J.A.P.; Soler, L.M. Relationship between the y Balance Test Scores and Soft Tissue Injury Incidence in a Soccer Team. Int. J. Sports Phys. Ther. 2015, 10, 955-966.

31. Hopkins, W.; Marshall, S.; Batterham, A.; Hanin, J. Progressive Statistics for Studies in Sports Medicine and Exercise Science. Med. Sci. Sports Exerc. 2009, 41, 3-13. [CrossRef]

32. Koo, T.K.; Li, M.Y. A Guideline of Selecting and Reporting Intraclass Correlation Coefficients for Reliability Research. J. Chiropr. Med. 2016, 15, 155-163. [CrossRef] [PubMed]

33. Espada, M.; Fernandes, C.; Martins, C.; Leitao, H.; Figueiredo, T.; Santos, F. Goal characterization after ball recovery in players of both genders of first league soccer teams in Portugal. Hum. Mov. 2018, 2018, 73-81. [CrossRef] 
34. Espada, M.; Figueiredo, T.; Ferreira, C.; Santos, F. Body Composition and Physical Fitness Analysis in Different Field Position U-15 Soccer Players. J. Phys. Educ. Sport 2020, 20, 1917-1924.

35. Hootman, J.M.; Dick, R.; Agel, J. Epidemiology of collegiate injuries for 15 sports: Summary and recommendations for in-jury prevention initiatives. J. Athl. Train. 2007, 42, 311-319. [PubMed]

36. Bayliss, A.; Weatherholt, A.; Crandall, T.; Farmer, D.; McConnell, J.; Crossley, K.; Warden, S. Achilles tendon material properties are greater in the jump leg of jumping athletes. J. Musculoskelet. Neuronal Interact. 2016, 16, 105-112. [PubMed]

37. Maloney, S.J. The Relationship Between Asymmetry and Athletic Performance: A Critical Review. J. Strength Cond. Res. 2019, 33, 2579-2593. [CrossRef]

38. Espada, M.C.; Alves, F.B.; Curto, D.; Ferreira, C.C.; Santos, F.J.; Pessôa-Filho, D.M.; Reis, J.F. Can an Incremental Step Test Be Used for Maximal Lactate Steady State Determination in Swimming? Clues for Practice. Int. J. Environ. Res. Public Health 2021, 18, 477. [CrossRef] [PubMed]

39. Madruga-Parera, M.; Bishop, C.; Read, P.; Lake, J.; Brazier, J.; Romero-Rodriguez, D. Jumping-based Asymmetries are Negatively Associated with Jump, Change of Direction, and Repeated Sprint Performance, but not Linear Speed, in Adolescent Handball Athletes. J. Hum. Kinet. 2020, 71, 47-58. [CrossRef]

40. Bishop, C.; Brashill, C.; Abbott, W.; Read, P.; Lake, J.; Turner, A. Jumping Asymmetries Are Associated With Speed, Change of Direction Speed, and Jump Performance in Elite Academy Soccer Players. J. Strength Cond. Res. 2021, 35, 1841-1847. [CrossRef]

41. Bishop, C.; Read, P.; McCubbine, J.; Turner, A. Vertical and Horizontal Asymmetries Are Related to Slower Sprinting and Jump Performance in Elite Youth Female Soccer Players. J. Strength Cond. Res. 2021, 35, 56-63. [CrossRef]

42. Björklund, G.; Alricsson, M.; Svantesson, U. Using Bilateral Functional and Anthropometric Tests to Define Symmetry in Cross-Country Skiers. J. Hum. Kinet. 2017, 60, 9-18. [CrossRef] [PubMed]

43. Rey, E.; Paz-Domínguez, Á.; Porcel-Almendral, D.; Paredes, V.; Barcala-Furelos, R.; Abelairas-Gómez, C. Effects of a 10-Week Nordic Hamstring Exercise and Russian Belt Training on Posterior Lower-Limb Muscle Strength in Elite Junior Soccer Players. J. Strength Cond. Res. 2017, 31, 1198-1205. [CrossRef]

44. Wik, E.H.; Mc Auliffe, S.; Read, P.J. Examination of Physical Characteristics and Positional Differences in Professional Soccer Players in Qatar. Sports 2018, 7, 9. [CrossRef]

45. Shaffer, S.W.; Teyhen, D.S.; Lorenson, C.L.; Warren, R.L.; Koreerat, C.M.; Straseske, C.A.; Childs, J.D. Y-Balance Test: A Reliability Study Involving Multiple Raters. Mil. Med. 2013, 178, 1264-1270. [CrossRef]

46. Gray, J.; Aginsky, K.D.; Derman, W.; Vaughan, C.L.; Hodges, P. Symmetry, not asymmetry, of abdominal muscle morphology is associated with low back pain in cricket fast bowlers. J. Sci. Med. Sport 2016, 19, 222-226. [CrossRef] [PubMed]

47. Hart, N.H.; Nimphius, S.; Weber, J.; Spiteri, T.; Rantalainen, T.; Dobbin, M.; Newton, R.U. Musculoskeletal Asymmetry in Football Athletes. Med. Sci. Sports Exerc. 2016, 48, 1379-1387. [CrossRef]

48. Croisier, J.-L.; Crielaard, J.-M. Hamstring muscle tear with recurrent complaints: An isokinetic profile. Isokinet. Exerc. Sci. 2000, 8, 175-180. [CrossRef]

49. Hewett, T.E.; Ford, K.; Xu, Y.Y.; Khoury, J.; Myer, G.D. Effectiveness of Neuromuscular Training Based on the Neuromuscular Risk Profile. Am. J. Sports Med. 2017, 45, 2142-2147. [CrossRef]

50. Ahmad, C.S.; Redler, L.H.; Ciccotti, M.G.; Maffulli, N.; Longo, U.G.; Bradley, J. Evaluation and Management of Hamstring Injuries. Am. J. Sports Med. 2013, 41, 2933-2947. [CrossRef]

51. Opar, D.A.; Williams, M.D.; Shield, A. Hamstring Strain Injuries. Sports Med. 2012, 42, 209-226. [CrossRef]

52. Price, R.; Hawkins, R.D.; Hulse, M.; Hodson, A. The Football Association medical research programme: An audit of injuries in academy youth football. Br. J. Sports Med. 2004, 38, 466-471. [CrossRef]

53. Woods, C.; Hawkins, R.D.; Maltby, S.; Hulse, M.; Thomas, A.; Hodson, A. The Football Association Medical Research Programme: An audit of injuries in professional football-analysis of hamstring injuries. Br. J. Sports Med. 2004, 38, 36-41. [CrossRef]

54. Bahr, R. No injuries, but plenty of pain? On the methodology for recording overuse symptoms in sports. Br. J. Sports Med. 2009, 43, 966-972. [CrossRef]

55. Henderson, G.; Barnes, C.A.; Portas, M.D. Factors associated with increased propensity for hamstring injury in English Premier League soccer players. J. Sci. Med. Sport 2010, 13, 397-402. [CrossRef]

56. Silder, A.; Reeder, S.; Thelen, D.G. The influence of prior hamstring injury on lengthening muscle tissue mechanics. J. Biomech. 2010, 43, 2254-2260. [CrossRef]

57. Macdonald, B.; O’Neill, J.; Pollock, N.; Van Hooren, B. Single-Leg Roman Chair Hold Is More Effective Than the Nordic Hamstring Curl in Improving Hamstring Strength-Endurance in Gaelic Footballers With Previous Hamstring Injury. J. Strength Cond. Res. 2019, 33, 3302-3308. [CrossRef]

58. Smith, C.A.; Chimera, N.J.; Warren, M. Association of Y Balance Test Reach Asymmetry and Injury in Division I Athletes. Med. Sci. Sports Exerc. 2015, 47, 136-141. [CrossRef]

59. Faigenbaum, A.D.; Lloyd, R.S.; Macdonald, J.; Myer, G.D. Citius, Altius, Fortius: Beneficial effects of resistance training for young athletes: Narrative review. Br. J. Sports Med. 2015, 50, 3-7. [CrossRef]

60. Palomares, B.R.A.; Palomares, E.M.D.G.; Uchoa, F.N.M.; Andrade, R.D.A.; Deana, N.F.; Alves, N. Effectiveness of the conju-gate influence method in improving static and dynamic balance in rhythmic gymnastics gymnasts. J. Phys. Educ. Sport 2019, 19, 1407-1417. [CrossRef] 
61. De Hoyo, M.; Sañudo, B.; Carrasco, L.; Mateo-Cortes, J.; Domínguez-Cobo, S.; Fernandes, O.D.J.; Del Ojo, J.J.; Gonzalo-Skok, O. Effects of 10-week eccentric overload training on kinetic parameters during change of direction in football players. J. Sports Sci. 2015, 34, 1-8. [CrossRef] [PubMed]

62. Eirale, C. Hamstring injuries are increasing in men's professional football: Every cloud has a silver lining? Br. J. Sports Med. 2018, 52, 1489. [CrossRef] [PubMed]

63. Hägglund, M.; Waldén, M.; Ekstrand, J. Previous injury as a risk factor for injury in elite football: A prospective study over two consecutive seasons. Br. J. Sports Med. 2006, 40, 767-772. [CrossRef] [PubMed]

64. Rodrigues, J.; Rodrigues, F.; Resende, R.; Espada, M.; Santos, F. Mixed Method Research on Football Coaches' Competitive Behavior. Front. Psychol. 2021, 12, 705557. [CrossRef] 